\title{
The Effects of Increased Workloads on Online Instruction
}

\author{
Georgianna Ravenna ${ }^{1, *}$ \\ ${ }^{1}$ California State University, Fullerton, Fullerton, CA, USA \\ * Correspondence: CalStateTEACH, California State University, Fullerton, 2600 E. Nutwood \\ Blvd. Suite 500, Fullerton, CA, USA
}

Tel: 1-657-278-4728Ｅ-mail: gravenna@fullerton.edu

Received: August 19, 2012 Accepted: September 29, 2012 Published: November 25, 2012 doi:10.5296/ije.v4i4.2269 URL: http://dx.doi.org/10.5296/ije.v4i4.2269

\begin{abstract}
The workload increase for California State University instructors has been significant, as has been the reduction in resources and support. Online instructors are facing the same set of circumstances as their campus-based peers, yet the impact of said circumstances has not been fully realized. Still most instructors want to do be effective in their teaching practices and will do what it takes to facilitate student learning. This paper examines the impact of budget cuts on online instructors, including increases in online class sizes and loss of student -instructor interaction. The research is clear regarding the importance of interaction in relation to academic success; however, it is mixed with regard to optimal online class size. The author suggests strategies to maintain teaching effectiveness during the current crisis by increasing interaction through the use of small group discussions, the use of facilitators, etc.
\end{abstract}

Keywords: online learning; online discussion; faculty workload; student engagement; interaction; class size; higher education 


\section{Introduction}

Recently, members of the California Faculty Association from the California State University system voted almost unanimously to engage in rolling strikes in response to the two-year impasse in contract negotiations between the CSU administration and the faculty association. In the last six years or so, CSU faculty has been saddled with increased class sizes, furloughs, and a reduction in resources and supplies (Orfield, 2011). The Civil Rights Project commissioned two studies to uncover the impact of these cutbacks on the CSU System. They found that the faculty surveyed were negatively impacted by the increase in class sizes and diminished overall support in the university system. The reports seem to reflect the thoughts and opinions of instructors teaching campus-based courses; however, online instructors and instructors who teach hybrid courses -both face to face and online-have also been negatively impacted by the cuts. The workload increase for these instructors has been significant and the reduction in resources and support palpable. Yet, regardless of this overwhelming set of circumstances, most instructors still want to be effective in their teaching practices. This paper will examine the impact of the budget crisis on online instructors. It will suggest strategies to maintain teaching effectiveness during the current crisis.

\section{Background}

\subsection{Budget Crisis}

California has suffered from a budget deficit for many years. Concurrently, the California State University system has experienced a recurring pattern of cuts to its state funding. According to a series of reports funded by the Civil Rights Project, state contributions to the CSU system have diminished by roughly $47 \%$ while tuition has increased by $103 \%$ (Orfield, 2011). The effects of these cuts to CSU faculty have been far reaching. Class sizes have increased dramatically; faculty has undergone a year of furloughs; resources have diminished; and morale is at an all time low. According to a faculty workload report from 2003, CSU faculty work harder than faculty in similar positions across the nation (CSU: Academic Research: Faculty Workload Reports, 3003). According to a faculty survey, faculty is doing more for a lot less. Moreover, their students are paying more for a lot less (Orfield, 2011).

\section{Research}

\subsection{Online and Hybrid Programs}

Campus-based class sizes have increased significantly across CSU programs, and instructors of online and hybrid courses are carrying heavier student loads, as well. Research suggests that teaching online courses requires more effort (Ascough, 2002; Drago \& Peltier, 2004). In addition, effective online instruction requires a sound knowledge of pedagogical principles that lead to higher order thinking and learning (Ascough, 2001). While it may not seem that adding students to an online course would make much difference (no space issues); 
this is simply not the case. There are more papers to grade; there is less direct contact with students; there are more students engage in discussions; and the instructor's ability to individualize instruction decreases. Hence the quality of education declines with expanding class sizes (Taft, Perkowski, \& Martine, 2011). Hybrid programs are even more impacted because instructors have to plan for online instruction, as well as for face-to-face meetings.

\subsubsection{Online Engagement and Class Size}

Although, there is no consensus in the literature as to the optimal online class size, there is considerable research to suggest that role of the instructor is key to student satisfaction and performance (Durrington et al., 2006), student engagement and ultimately student learning (Ryan \& Scott, 2008). The Community of Inquiry model will be used to frame the body of research in relation to online engagement. Garrison, and Arbaugh (2007) developed the Community of Inquiry framework, in which they posit that three elements are necessary in online environments to ensure learning: social presence, cognitive presence and teaching presence. Social presence refers to the students' ability to project themselves as true learners, socially and emotionally, in an online environment. Cognitive presence can be explained as the degree to which learners can create meaning through learning and discussion-related activities. Teaching presence can be defined as the construction, facilitation, and focus of cognitive and social processes in order to create meaningful learning outcomes. Of note in this framework is the teacher's role, which is pivotal to achieving learning outcomes. The teacher's social presence and instruction influence cognitive presence and social presence. Moreover, the teacher's course design and interactive role creates the teaching presence.

The literature confirms that student interaction is an essential component of online learning (Bannan-Ritland, 2002; Swan, 2001; Wanstreet, 2006), and the more interactive the course, the higher the level of student satisfaction and performance (Durrington, Berryhill, \& Swaffor, 2006). A meta-analysis of online interaction maintained that increasing interaction positively affects student achievement (Bernard, 2009). Hence, the importance of interaction in online learning has been clearly established. The review of literature will focus on teaching presence, as this is the aspect of teaching most impacted by the budget cuts.

\subsubsection{Teaching Presence}

Teaching presence refers to how the teacher structures the course, facilitates interaction and instructs in order to impart information. Studies have also confirmed that teaching presence contributes greatly to students' level of satisfaction, sense of community and learning within a course (Garrison \& Arbaugh, 2007). Paulus and Roberts (2006) examined online discussion data from a preservice teacher psychology course. Students were randomly assigned to groups of four to complete three case study analyses over a 15-week period. There were 31 students in the section studied. The course consisted of asynchronous discussions and synchronous chats. The first case involved a discussion; in the second case, students engaged in a chat; and in the third case, students were allowed to choose the type of discussion. The groups were self-facilitated; no roles were assigned and the instructor was available for questions. The most and least successful groups were studied. Participation data and functions in the conversations were coded, and student reflections were examined. The 
members of the most successful group participated fully in the discussions; they posted more responses and their conversations revealed a larger number and variety of functions. The low achieving group was quick to finish the task; they did not engage in any additional social interaction. Paulus and Roberts (2006) noted that trust building was an important component to increasing student interaction online. They suggested the use of introductory activities or a face-to-face component. They also mentioned maintaining the same groups throughout the semester, so that students learn how to work together effectively. Students involved in more supportive environments tended to delve deeper into discussion topics. Lastly, they suggested that the discussions be purposefully designed and that a facilitator might be necessary to model effective discourse and promote higher levels of discussion.

Dutt-Doner and Powers (2000) used three sections (68 students) of a teaching methods course to study newsgroups (electronic discussions). Participants were required to post at least five initial responses and five follow up replies over the course of the semester. The researchers used multiple methods to collect qualitative data. First, the messages from the newsgroup discussions were content analyzed and thematically grouped. Next, the researchers asked students to write about what they liked and did not like about the newsgroup. This information was also content analyzed and grouped thematically. Then, they held a debriefing session where students were asked a series of open-ended questions about their experience. This session was videotaped, transcribed, and analyzed. Last, the instructor also maintained a journal documenting the experience, and the researchers met to discuss their observations, as well.

The findings suggested that students developed a sense of community through the online discussions, in which they were highly participatory and supportive of their classmates. The discussion responses indicated that students felt comfortable with online communication and also reflected an exchange of ideas pertinent to field experiences and prior classroom discussions. According to the researchers, there were some specific factors that bolstered the success of this newsgroup. Requiring student participation was one such example. Instructor encouragement also played a role in increased engagement, as did having the instructor act as a participant rather than a facilitator. Dutt-Doner and Powers (2000) proposed that the instructor become an active participant in the discussions.

The importance of instructor modeling and clear guidelines was also documented by Knapczyk \& Hew (2007). Knapczyk and Hew (2007) examined six online activities in a graduate methods course. The activities focused on objectives normally covered in the teacher education coursework. In the first activity, one student was a starter and another was a wrapper. In the second activity, specific assignments were given regarding methods. In the third activity, students were grouped to discuss a specific case study. The fourth activity was a debate; the fifth activity asked students to examine and apply intervention methods, and the last activity was a chat. There were 33 participants involved in this study. The instructors conducted a face-to-face meeting at the start of the course to state objectives of the course, meet the students, and give general directions. In addition, there were two more face-to-face meetings during the course. Synchronous and asynchronous discussions were used, and there was an assessment rubric for each objective. A questionnaire and a set of open-ended 
questions were also administered at the end of the course. The assessment results indicated that the majority (91\%) of students achieved the activity objectives. Eighty percent of the students also indicated an overall satisfaction with the online method; and $86-90 \%$ of students perceived the first five activities to be positive, interactive learning experiences. The sixth activity, the chat format, proved to be less successful for a variety of reasons. This study did not control for the differences in the difficulty level, the sequence and the amount of work required for each activity. These factors may have affected the study results. From this experience, the researchers noted the importance of appropriate time allotment for activities. In addition, they proposed including specific guidelines for discussion and modeling of appropriate interaction skills, in conjunction with fixed times for online chats involving focused topics.

A case study by Vonderwell (2003) also recognized the role of the instructor in online discussions. Vonderwell (2003) studied the experiences of pre-service teachers in an asynchronous online course. This qualitative case study included 22 students in one section of a technology in education course. The course included six small discussion groups in which students responded to specific prompts. The researcher gathered information from student interviews, student and instructor email messages, discussion board posts, and the reviews of two independent peers, and then analyzed the data thematically. Some students reported that they missed the immediate feedback and personal relationship with the instructor. They also felt that they did not learn from their peers in the online discussions. Others enjoyed the peer interaction and felt that this interaction, in fact, promoted learning. Students indicated that the asynchronous format facilitated student to instructor interaction, because they were more comfortable asking questions of the instructor under such conditions of anonymity. Students solicited "interpersonal and social relationships with their instructor" (p. 12). Suggestions to increase interaction included prompt instructor feedback, clear explanations of assignments and expectations, and the use of strategies to promote student collaboration and the formation of an online community.

Last, the theme of the instructor as a participant or facilitator in the online discussion was prevalent. The level of interaction and/or depth of discussion increased when either the instructor or a designated student took on a leadership role in the discussion, either as a moderator, or as a facilitator to encourage further reflection on the topic being explored (Ikpeze, 2007; Im \& Lee, 2003-2004; Lee-Baldwin, 2005; Li, 2006; Nonis et al., 2000; Paulus \& Roberts, 2006). Dutt-Doner \& Powers (2000) and Nonis et al. (2000) also emphasized the importance of instructor participation in the discussion; however, as a fellow participant rather than a mediator. The finding was based on the notion that in this situation, students gained a sense of control and therefore participated more freely in the online conversation.

The role of the instructor as an active participant was also prominent in the research. The data collected by Dutt-Doner and Powers (2000) revealed three key components to effective online participation: 1) Student participation needed to be a requirement; 2) The instructor encouraged active participation; 3) When the instructor acted as a participant rather than a moderator, she was able to contribute to the discussion without being judgmental. In this way, 
the instructor was also able to model appropriate responses. The role of the instructor or group facilitator was also emphasized in Ikpeze's (2007) work. The group facilitator served to facilitate active learning by moderating participant interaction, unifying students' responses, and inciting further discussion. $\mathrm{Li}$ (2006) added that an "elevated social presence" on the part of the teachers increased social and academic engagement in the discussion forums (p. 12). Although, An et al. (2009) concurred regarding the importance of the instructor's presence in discussion forums, they also cautioned against too much instructor intervention. In some cases, excessive commentary by the instructor decreased student to student interaction.

\subsubsection{Class Size and Instructor Presence}

Previous studies of online class sizes have yielded mixed results for online class sizes in relation to learning. A review of the literature by Taft, Perkowski, \& Martin (2011) revealed that that online class sizes in excess of 30 students become less individualized and interactive; many researchers suggest somewhere in the range of 15-30 students as the optimal online class size.

Yet, to increase cognitive engagement with course concepts and to extend learning in an online environment, a visible and active instructor presence and interaction was requisite, as was a structured learning environment (Dutt-Doner \& Powers, 2000; Im \& Lee, 2003-2004; Lee-Baldwin, 2005; Ryan \& Scott, 2008; McLoughlin \& Mynard, 2009; Paulus \& Roberts, 2006). Hence, deeper learning requires more student-instructor interaction and therefore smaller class sizes, while classes that require less high-order thinking may suffice with larger numbers.

\section{Discussion and Implications}

The body of research points to student interaction as an essential component of online learning, and the increase in the level of interactivity directly correlates with a higher the level of student satisfaction and performance (Durrington at al., 2006). It is clear from the literature that the instructor needs to make a conscious decision about the desired outcome of the online learning. If the instructor desires to simply have an electronic means of creating a social connection between students and the instructor, this needs to be decided when constructing the discussions. Alternatively, if the goal is to create higher-level thinking and a thought-provoking discussion, then this should be the intent of the discussion when constructed (McLoughlin \& Mynard, 2009). If the intent of the instructor is to actively involve students in the online discussions, a number of studies focused on the effective use of student-instructor interaction in this online environment. As this is a common element in many online courses, it is important to examine the implications for effective design by enhancing this form of interaction. Ryan and Scott (2008) asserted that an increase in instructor participation in an online environment resulted in increased student learning. The design of the course should include varied avenues for instructor participation including interactive study guides, video and audio presentations, case studies, open-ended activities, 
engaging discussions which establish the instructor as an active participant, and activities that require engaged higher-level thinking and application of learning. The role of the instructor can be pivotal in combining the tools of the course to create a community of learners online by engaging the students in more than the basic content of the course or completion of activities. The ability to create this online community, and trust building, is noted as an essential component through the use of introductory activities or a face-to-face component in the course (Paulus \& Roberts, 2006). Creating additional avenues through interpersonal discussions, sharing of personal pictures, collegial discussions centered around the profession and not necessarily on the content, and instructor facilitation can lead to increased student engagement and the building of an online community. This information is essential to programs where the cohort model is used and lends itself well to developing such an online community of learners.

The ability to create an online community of learners and engage students through meaningful and relevant interactions is well defined by several studies. The roles of interactions between students and instructor can be clearly defined to create engagement and increased levels of cognition, which extend beyond the classroom. Both the student and the instructor must have clearly defined roles, focused on the most effective strategies that increase interaction. Moreover, with higher student to instructor ratios per class, it is imperative for the instructor to create opportunities for smaller group interaction and individualized attention. The use of a facilitator or group moderator has been found to be effective in stimulating interaction and promoting further discussion (Ikpeze, 2007). Instructors may also consider the use of strategies such as literature circles (Daniels \& Steineke, 2004) to introduce texts of relevance and interest, or The World Café as a means to build community (Welcome to the World Cafe, n.d.). Lastly, instructors may look for support from their peers. There are many professional development opportunities available to increase knowledge and build support in the university community.

\section{References}

An, H., Shin, S., \& Lim, K. (2009). The effects of instructor facilitation approaches on students' interactions during asynchronous online discussions. Computers \& Education, 53, 749-760. http://dx.doi.org/10.1016/j.compedu.2009.04.015

Ascough, R.S. (2002). Designing for online distance education: Putting pedagogy before technology. Teaching Theology and Religion, 5(1), 17-29. http://dx.doi.org/10.1111/1467-9647.00114

Baldwin, J. L. (2005). Asynchronous Discussion Forums: A closer look at structure, focus, and group dynamics that facilitate reflective thinking. Contemporary Issues in Technology and Teacher Education, 5(1).

Bannan-Ritland, B. (2002). Computer-mediated communication: A review of the research. The Quarterly Review of Distance Education, 3(2), 161-179.

Bernard, R. M., Abrami, P.C., Borokhovski, E., Wade, C.A., Tamin, R.M., Surkes, M.A., \& 
Bethel, E.C. (2009). A meta-analysis of three types of interaction treatments in distance education. Review of Educational Research, 79(3), 1243-1289. http://dx.doi.org/10.3102/0034654309333844

CSU: Academic Research: Faculty Workload Reports (Rep.). (2003). Retrieved May 16, 2012, from Advisory Committee for the CSU website: http://www.calstate.edu/acadres/csuFacWkLoad.shtmlBiesenbach-Lucas， S. (2004). Asynchronous we discussions in teacher training courses: Promoting collaborative learning-or not? Association for the Advancement of Computing in Education Journal, $12(2), 155-170$.

Daniels, H., \& Steineke, N. (2004). Mini-lessons for literature circles. Portsmouth, NH: Heinemann.

Drago, W., \& Peltier, J. (2004). The effects of class size on effectiveness for online courses. Management Research News, 27(10), 27-41. http://dx.doi.org/10.1108/01409170410784310

Durrington, V. A., Berryhill, A., \& Swaffor, J. (2006). Strategies for enhancing interactivity in an online environment. College Teaching, 54(1), 190-193. http://dx.doi.org/10.3200/CTCH.54.1.190-193

Dutt-Doner, K. M., \& Powers, S.M. (2000). The use of electronic communication to develop alternative avenues for classroom discussion. Journal of Technology and Teacher Education, 8(2), 153-172.

Garrison, D.R., \& Arbaugh, J.B. (2007). Researching the community of inquiry framework: Review, issues, and future directions. Internet and Higher Education, 10, 157-172.Ferdig, R. E., \& Roehler, L.R. (2003). Student uptake in electronic discussions: Examining online discourse in literacy preservice classrooms. Journal of Research on Technology in Education, 36(2), 119-136. http://dx.doi.org/10.1016/j.iheduc.2007.04.001

Ikpeze, C. (2007). Small group collaboration in peer-led electronic discourse: An analysis of group dynamics and interactions involving preservice and inservice teachers. Journal of Technology and Teacher Education, 15(3), 388-407.

Im, Y., \& Lee. O. (2003-2004). Pedagogical implications of online discussion for preservice teacher training. Journal of Research on Technology in Education, 36(2).

Knapczyk, D. R., \& Hew, K.F. (2007). An analysis and evaluation of online instructional activities. Teacher Education and Special Education, 30(3), 167-182. http://dx.doi.org/10.1177/088840640703000305

Lee-Baldwin, J. (2005). Asynchronous Discussion Forums: A closer look at structure, focus, and group dynamics that facilitate reflective thinking. Contemporary Issues in Technology and Teacher Education, 5(1).

Li, Q. (2006). Integrating online discussion: Broadening the conversation. Contemporary Issues in Technology and Teacher Education, 6(2). 
McLoughlin, D., \& Mynard, J. (2009). An analysis of higher order thinking in online discussions. Innovations in Education and Teaching International, 46(2), 147-160. http://dx.doi.org/10.1080/14703290902843778

Nonis, A. S., Bronak, S.C., \& Heaton, L. (2000). Web-based discussions: building effective electronic communities for preservice technology education. Journal of Technology and Teacher Education, 8(1), 3-11.

Orfield, G. (Ed.). (2011). The CSU Crisis and California's Future. Los Angeles, CA: The Civil Rights Project/Proyecto Derechos Civiles at UCLA. www.civilrightsproject.ucla.edu

Paulus, T. M., \& Roberts, G. (2006). Learning through dialogue: Online case studies in educational psychology. Journal of Technology and Teacher Education, 14(4), 731-754.

Ryan, J., \& Scott, A. (2008). Integrating technology into teacher education: How online discussion can be used to develop informed and critical literacy teachers. Teaching and Teacher Education, 24, 1635-1644. http://dx.doi.org/10.1016/j.tate.2008.02.012

Swan, K. (2001). Virtual interaction: Design factors affecting student satisfaction and perceived learning in asynchronous online courses. Distance Education, 22(2), 306-331. http://dx.doi.org/10.1080/0158791010220208

Taft, S.H., Perkowski, T., \& Martin, L.S. (2011). A framework for evaluating class size in online education. The Quarterly Review of Distance Education, 12(3), 181-197.

U.S. Department of Education, O. o. P., Evaluaton, and Policy Development. (2009). Evaluation ofevidence-based practices in online learning: A meta-analysis and review of online learning studies (No. ED-04-CO-0040).

Vonderwell, S. (2003). An examination of asynchronous communication experiences and perspectives of students in an online course: a case study. The Internet and Higher Education, 6(1), 77-90. http://dx.doi.org/10.1016/S1096-7516(02)00164-1

Wanstreet, C. E. (2006). Interaction in online learning environments: A review of the literature. The Quarterly Review of Distance Education, 7(4), 399-411.

Welcome to the World Cafe. (n.d.). Retrieved May 15, 2012, from http://theworldcafe.com/

\section{Copyright Disclaimer}

Copyright reserved by the author(s).

This article is an open-access article distributed under the terms and conditions of the Creative Commons Attribution license (http://creativecommons.org/licenses/by/3.0/). 